\title{
STUDI MORFOLOGI DAN GEOLOGI KAWASAN KARST DALAM PENGEMBANGAN KONSEP GEOPARK DAERAH SILOKEK, KABUPATEN SIJUNJUNG, SUMATERA BARAT
}

\author{
Ahmad Fadhly ${ }^{1)}$, Dian Hadiyansyah ${ }^{2)}$ \\ ${ }^{12}$ Jurusan Teknik Pertambangan, Sekolah Tinggi Teknologi Industri Padang \\ e-mail : ahmadfadhly.geo08@yahoo.com
}

\begin{abstract}
Abstrak
Abstrak : Kawasan Silokek memiliki obyek dan unsur geopark Kawasan geopark itu sendiri meliputi unsur geologi, flora fauna dan budaya lokal. Unsur-unsur tersebut semua ada di kawasan Silokek dengan geologi yang berupa tebing-tebing dan goa, hal ini teridentifikasi pada saat Geopark silokek ditetapkan menjadi kawasan Geopark Nasional pada tahun 2018, sehingga terbuka bagi penulis untuk dapat mengidentifikasi kawasan untuk pembangunan daerah dari sisi ilmu kebumian. Pola pengembangan geopark secara umum adalah tidak terlepas dari konsep konservasi dan edukasi. Salah satu kendala adalah minimnya informasi mengenai kondisi geologi dan geomorfologi daerah sekitar Silokek untuk menjadi potensi wisata dan dampak ekonomi masyarkat. Tujuan penelitian ini adalah mengidentifikasi variabel geologi, geomorfologi, lingkungan di Silokek, mengkaji karakteristik umum setiap variabel geologi, geomorfologi, lingkungan yang menjadi indikator kunci (key-indicator) dalam menentukan daerah potensi wisata dengan konsep geopark di Silokek. Metode penelitian yang dilakukan terdiri dari beberapa tahapan meliputi pengumpulan data sekunder berupa geologi regional dan peta kawasan geopark, pengumpulan data primer berupa data kegiatan lapangan, analisis laboratorium untuk mengolah data lapangan dan data geomorfologi. Hasil yang didapat berupa pola pengembangan wilayah berbasis geopark yang telah teridentifikasi dari data geologi dan geomorfologi kawasan.
\end{abstract}

Kata kunci: Geopark, Konservasi, Penataan Wilayah, Geologi dan Geomorfologi

\begin{abstract}
Silokek area has geopark objects and elements. The geopark area itself includes elements of geology, flora, fauna and local culture. These elements are all present in the Silokek area with geology in the form of cliffs and caves, this was identified when the Silokek Geopark was determined to be the National Geopark area in 2018, so it is open for authors to be able to identify areas for regional development in terms of geoscience. . The geopark development pattern in general is inseparable from the concept of conservation and education. One of the obstacles is the lack of information regarding the geological and geomorphological conditions of the area around Silokek to become tourism potential and the economic impact of the community. The purpose of this study is to identify the geological, geomorphological, and environmental variables in Silokek, to study the general characteristics of each geological, geomorphological, and environmental variable which are key indicators in determining tourism potential areas with the geopark concept in Silokek. The research method consists of several stages; includes secondary data collection in the form of regional geology and maps of geopark areas, primary data collection in the form of field activity data, laboratory analysis to process field data and geomorphological data. The results obtained are in the form of geopark-based regional development patterns that have been identified from geological and geomorphological data of the area.
\end{abstract}

Keywords : Geopark, Conservation, Regional Planning, Geology and Geomorphology 


\section{PENDAHULUAN}

Silokek merupakan kawasan yang menarik dengan fenomena alamnya dan jadi pembahasan menarik dalam keilmuan untuk menarasikan berdasarkan keterjadiannya, silokek sendiri terletak di bagian Timur dari Kota Padang dan merupakan bagian dari perbatasan antara Sawahlunto dan Kabupaten Solok lebih tepatnya terletak pada titik koordinat $00^{\circ} 37 ' 58,9^{\prime \prime S}$ (Lintang Selatan) / 10059'47.3"E (Bujur Timur). Objek geologi yang tentu saja mampu menghipnotis para pengunjung dengan keindahan serta udara nan sejuk ini bernama Silokek. Nama Silokek diambil dari nama nagari (desa) Silokek, berlokasi di pinggiran hutan, membuat Silokek memiliki potensi wisata yang sangat tinggi.

Pengembangan kawasan Geopark melalui konsep pariwisata diaplikasikan sebagai instrumen pembangunan daerah secara berkelanjutan yang mendasarkan pada aspek konservasi, pendidikan, penumbuhan nilai ekonomi lokal (salah satunya melalui pariwisata), dan keterlibatan masyarakat setempat secara aktif. Berdasarkan peran geopark dalam kebutuhan masyarakat, penelitian ini bertujuan untuk mengungkap karakteristik geologi, geomorfologi, lingkungan, tata ruang dan wilayah daerah Silokek secara spesifik dengan menggunakan pendekatan Sistem Informasi Geografis, seperti, mengungkap variabel geologi geomorfologi - lingkungan di Silokek, mengkaji karakteristik umum setiap variabel geologi - geomorfologi - lingkungan yang menjadi indikator kunci (key-indicator) dalam menentukan daerah potensi di Silokek.

Mengidentifikasi dan mengevaluasi dampak yang ditimbulkan terhadap ruang dan kegiatan manusia sekitar, mengembangkan program sadar wisata dan lingkungan bagi warga yang bermukim di sekitar kawasan Geopark Silokek, mengetahui kondisi daerah yang layak bagi masyarakat tentunya menjadi suatu hal baik bagi masyarakat setempat untuk mengembangkan taraf hidup dan pekerjaan yang lebih baik.

\section{METODOLOGI}

Metode penelitian yang dilakukan terdiri dari beberapa metode; meliputi pengumpulan data sekunder berupa geologi regional dan peta kawasan geopark, pengumpulan data primer berupa data kegiatan lapangan, analisis laboratorium untuk mengolah data lapangan dan data geomorfologi. Tahap pendahuluan sebelum melakukan penelitian dan pengambilan data lapangan, meliputi studi regional daerah penelitian untuk mengetahui gambaran umum tentang data geologi daerah penelitian, sehingga kegiatan lapangan sangat membantu dalam mendukung kompilasi data sekunder sebagai dasar utama dalam penelitian.

Penelitian ini mengacu pada beberapa disiplin ilmu berbeda namun pada prinsipnya bidang geologi - geomorfologi dan relevansi dari beberapa cabang terapan ilmu lain digunakan sebagai basis untuk mengarahkan dan memfokuskan penelitian ini.

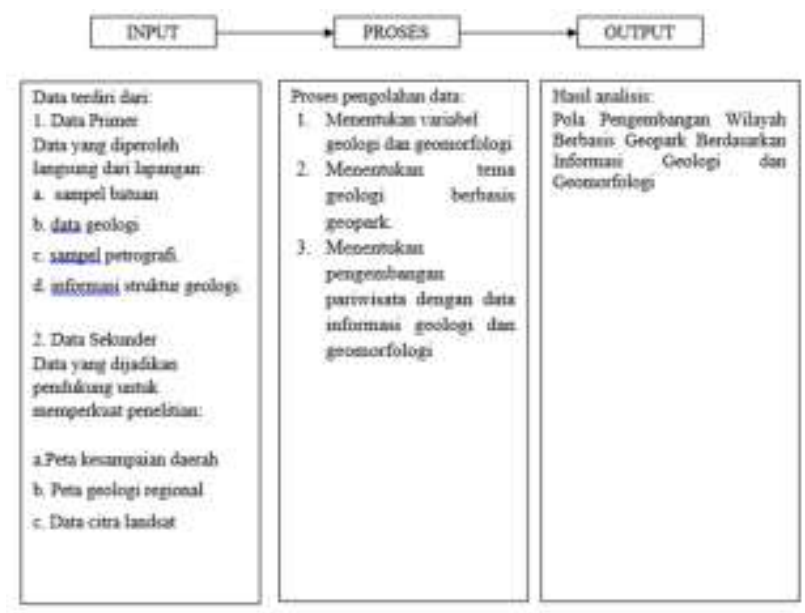

Gambar 1. Kerangka Konseptual Penelitian 


\section{HASIL DAN PEMBAHASAN}

\section{Pengambilan Conto Endapan Aktif dan Pengamatan Geologi}

Pengamatan geologi di sekeliling sungai, yang tersusun oleh batuan beku yang mendominasi litologi daerah ini. Secara megaskopis, warna lapuk abu-abu, warna segar abu-abu keputihan, hipokristalin, Porfiritik - faneritik, inequigranular, keras, struktur masif. Komposisi mineral yang dapat terlihat adalah kuarsa,plagioklas, feldspar dan terlihat mineral gelas.. satuan batuan ini tersebar di bagian tengah - utara daerah penyelidikan yang menempati daerah morfologi perbukitan terjal.

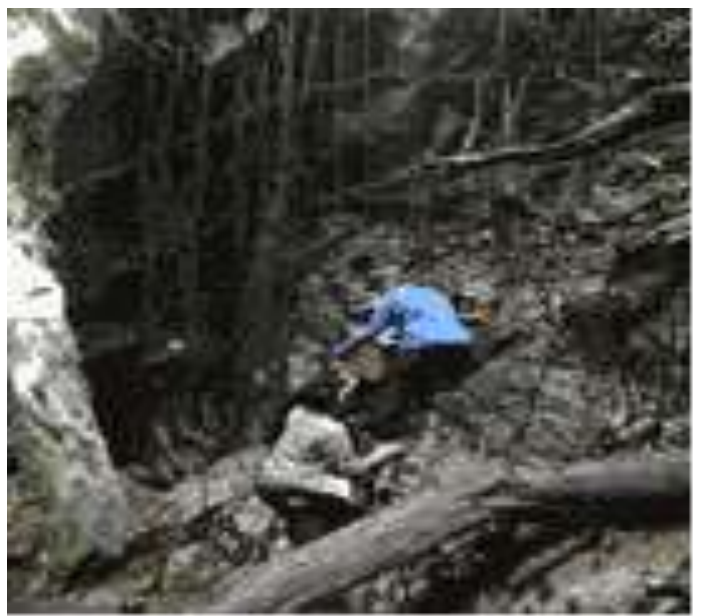

Gambar 2. Pengambilan Sampel Batuan

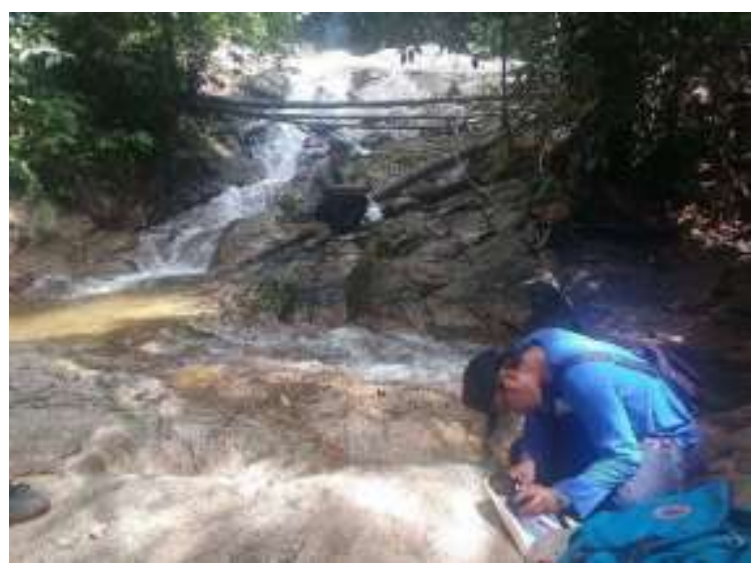

Gambar 3. Pengambilan Sampel Batuan
Pada umumnya batuan ini tersingkap pada lereng-lereng sungai di bagian hulu yang berlereng terjal, seperti yang tersingkap di hulu Ake Welwalebesbisele pada lokasi 17/HT/0279A (Gambar 4), Secara lengkap deskripsi megaskopis dari batu gamping ini, yaitu warna segar putih, warna lapuk cokelat, struktur berlubang - lubang akibat pelarutan, besar butir halus, bentuk butir membundar - membundar tanggung, kemas terbuka, komposisi penyusun batuan terdiri dari alga dan foram.

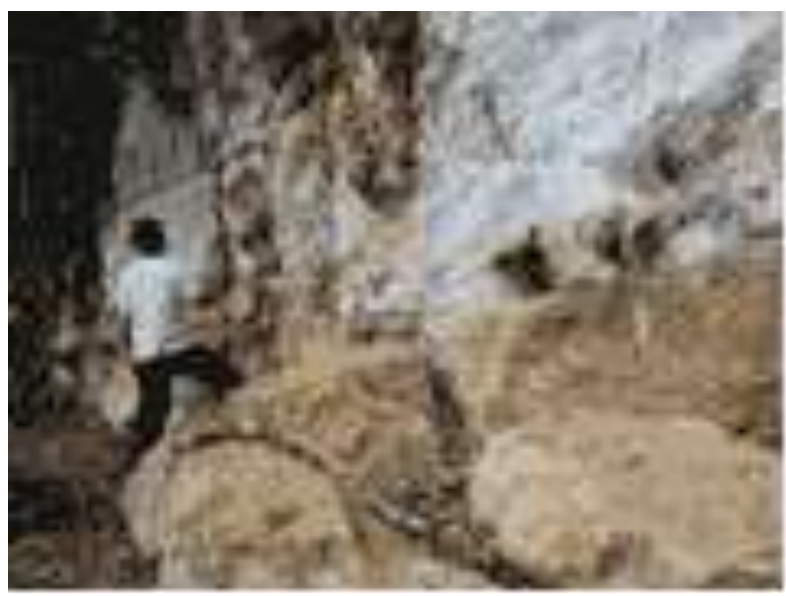

Gambar 4. Pengambilan Sampel Batuan Gamping

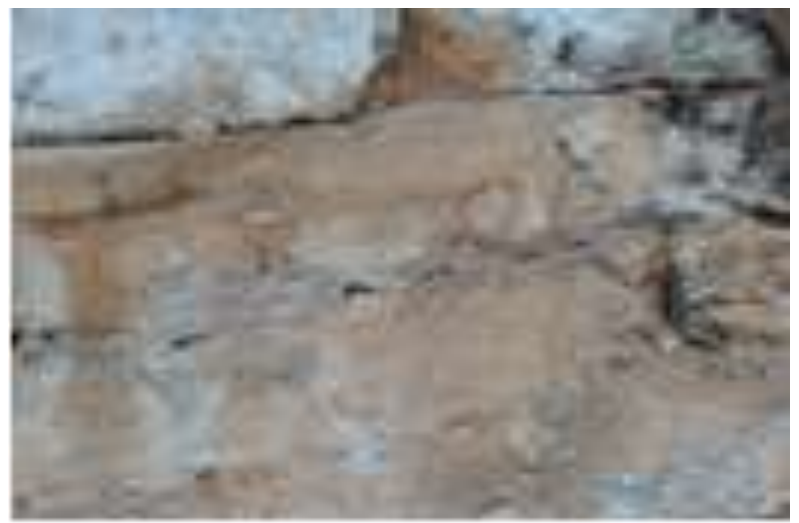

Gambar 5. Pengambilan Sampel Batuan Gamping

\section{Geomorfologi Daerah Penelitian}

Analisis geomorfologi yang dilakukan dilakukan dengan menggunakan data peta 
rupabumi dengan skala 1:25.000, serta citra satelit. Penentuan satuan geomorfologi didasarkan atas aspek relief, pola pengaliran, morfogenetik, serta morfometri.

Dalam pendeliniasian relief di daerah penelitian digunakan citra radar DEM SRTM untuk memberikan kesan 3 dimensi. Hasil dari pendeliniasian relief kemudian digunakan sebagai dasar dalam penentuan satuan geomorfologi daerah penelitian, yang memiliki nilai atau atribut morfografi (aspek deskriptif) dan morfometri (aspek kuantitatif) yang berbeda.

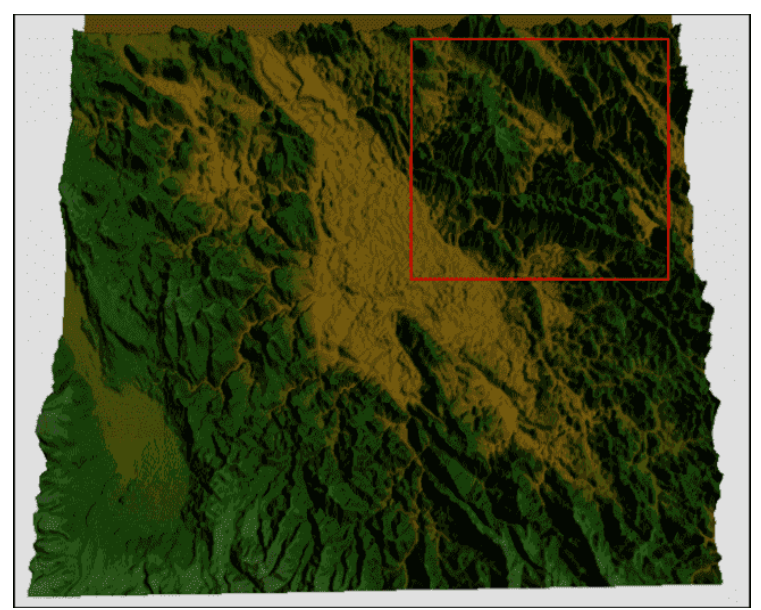

Gambar 6. Kenampakan Citra Kawasan Penelitian

Berdasarkan kemiringan lerengnya, satuan geomorfologi daerah penelitian terbagi menjadi tiga satuan, yaitu :

1. Satuan Geomorfologi Pedataran Aluvium

2. Satuan Geomorfologi Perbukitan Struktural

3. Satuan Geomorfologi Denudasional

4. Satuan Geomorfologi Karst

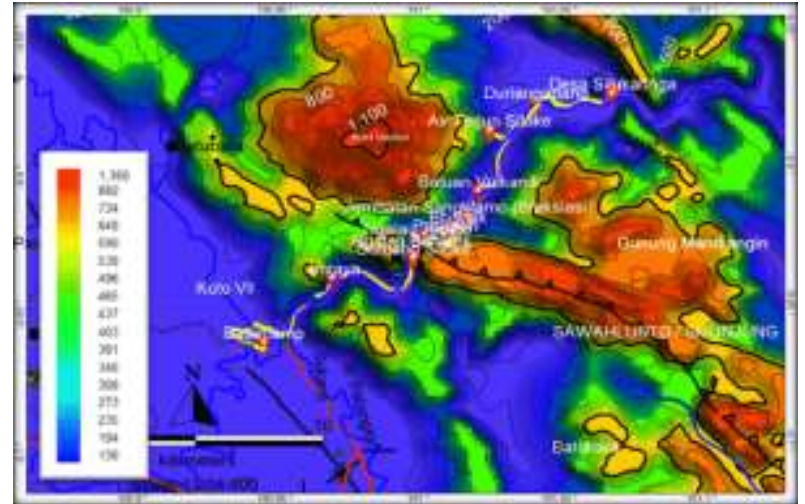

Gambar 7. Kenampakan Citra Kawasan Penelitian

\section{Pedataran Aluvium}

Dataran banjir berada pada sisi sungai, dataran lembah sempit diantara perbukitan, Berada pada sisi sisi sungai diantara dua punggungan bukit.

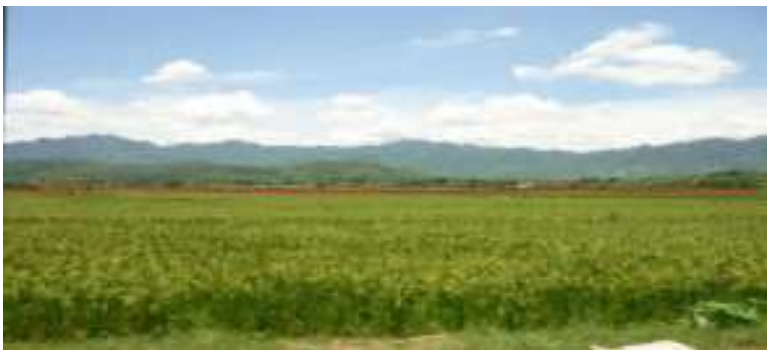

Gambar 8. Satuan geomorfologi pedataran

\section{Perbukitan Struktural}

Dataran hingga perbukitan lipatan, Dominan disusun oleh material batuan dari Anggota Bawah formasi Ombilin yang teridiri dari Lempung dan napal dengan sisipan batupasir, konglomerat mengandung kapur dan berfosil. Dominasi lempung dan napal pada wilayah ini menghasilkan kawasan yang relatif datar hingga landai dengan sedikit perbukitan di bagian tepinya. Topografi datar hinga landai dengan kelerengan $<5 \%$. 


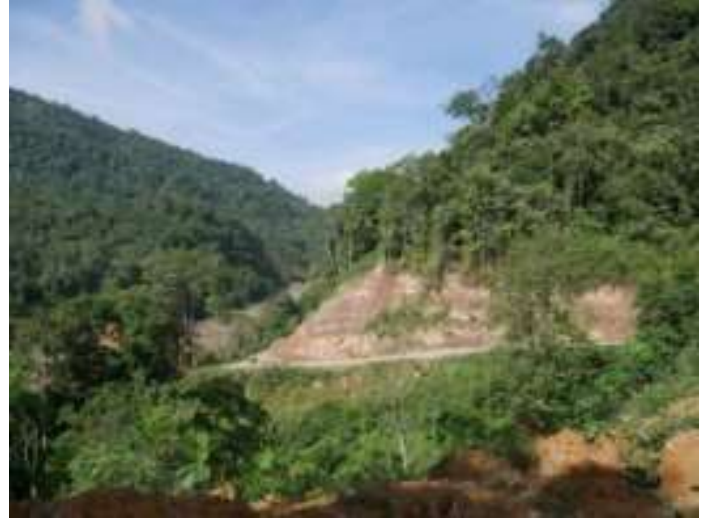

Gambar 9. Satuan Geomorfologi Perbukitan Struktural

\section{Perbukitan Karst}

Dataran kapur dengan lahan agak bergelombang, Merupakan daerah yang umumnya berupa dataran bergelombang secara setempat-setempat, litologi terdiri dari batukapur. Kawasan ini umumnya dibatasi oleh tinggian-tinggian berlereng terjal hingga dinding-dinding batu. Tebing-tebing memanjang dan menjulang tinggi sangat umum dijumpai. Dibagian tengah kawasan ini umum terbentuk depresi atau cekungancekungan tetutup pada tubuh batukapur dengan lubang ponor di bagian dasar cekungan sebagai tempat lolosnya air permukaan ke dalam tubuh batuan karst membentuk aliran aliran sungai.

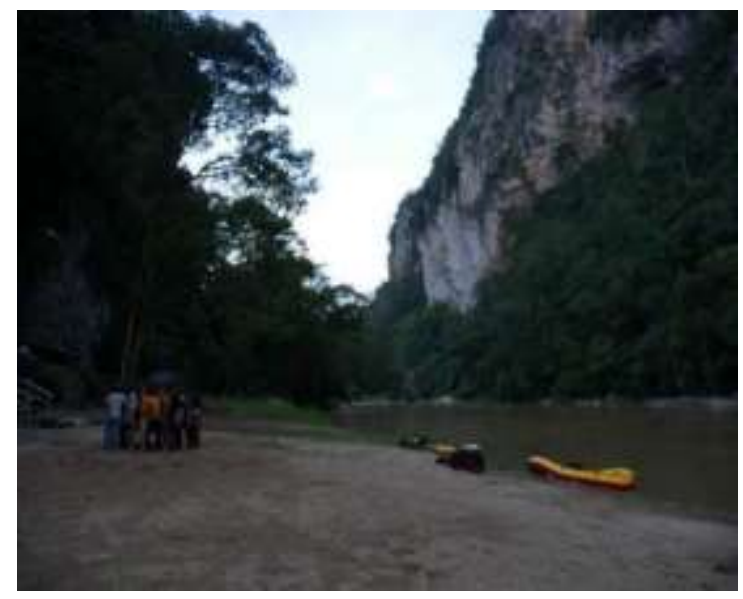

Gambar 10. Tebing Karst Dengan Tinggi 200 450 Mwss
Tabel 1. Kolom Geomorfologi

\begin{tabular}{|c|c|c|c|c|c|c|c|c|c|}
\hline \multirow[b]{3}{*}{$\begin{array}{c}\text { Satuat } \\
\text { Gountaridef }\end{array}$} & \multicolumn{9}{|c|}{ 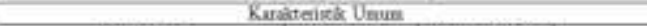 } \\
\hline & \multicolumn{4}{|c|}{ Marfarafi } & \multicolumn{2}{|c|}{ Serfinatsi } & \multicolumn{2}{|c|}{ Masfagenerik } & \multirow[b]{2}{*}{$\begin{array}{l}\text { Matenial } \\
\text { Pexpueun }\end{array}$} \\
\hline & $\begin{array}{l}\text { Warea } \\
\text { Simbo } \\
1\end{array}$ & $\begin{array}{l}\text { Bentok } \\
\text { Lathe }\end{array}$ & $\begin{array}{l}\text { Bearu } \\
k \\
\text { Lewb: } \\
\text { a }\end{array}$ & $\begin{array}{l}\text { Pola } \\
\text { Peng } \\
\text { aling }\end{array}$ & $\begin{array}{l}\text { Kering } \\
\text { gian } \\
\text { (mi) }\end{array}$ & $\begin{array}{l}\text { Keni } \\
\text { tagga } \\
\text { a } \\
\text { Lenen } \\
\text { a } \\
\rho\end{array}$ & $\begin{array}{l}\text { Endest } \\
\text { in }\end{array}$ & $\begin{array}{l}\text { Ekwg } \\
\text { a }\end{array}$ & \\
\hline $\begin{array}{l}\text { Pedaraw } \\
\text { Ahvim }\end{array}$ & & $\begin{array}{l}\text { Pedstare } \\
\text { in }\end{array}$ & U & $\begin{array}{l}\text { Anant } \\
\text { cmanti } \\
k \\
\text { Subp } \\
\text { mald }\end{array}$ & $\begin{array}{l}100- \\
150\end{array}$ & $0-2$ & & Eraul & Aluvium \\
\hline $\begin{array}{l}\text { Petrikitan } \\
\text { Struktraral }\end{array}$ & & $\begin{array}{l}\text { Partukit } \\
\text { an }\end{array}$ & $\mathrm{U}-\mathrm{V}$ & $\begin{array}{l}\text { vabde } \\
\text { tatiti } \\
\text { K }\end{array}$ & $\begin{array}{l}200- \\
\$ 90\end{array}$ & s- & tumai & Erual & $\begin{array}{l}\text { Garpisa. } \\
\text { Grani. }\end{array}$ \\
\hline kanst & & $\begin{array}{l}\text { Petrabir } \\
\text { an - } \\
\text { Pepaum } \\
\text { gm }\end{array}$ & v & $\begin{array}{l}\text { Sebt } \\
\text { endin } \\
k \\
\text { 5ubp } \\
\text { andel }\end{array}$ & $\begin{array}{l}250 . \\
516\end{array}$ & $\begin{array}{l}20- \\
35\end{array}$ & $\begin{array}{l}\text { Telse } \\
\text { nike }\end{array}$ & Eraé: & samping \\
\hline
\end{tabular}

\section{Geologi Daerah Penelitian}

Dalam pembahasan stratigrafi daerah penelitian, penulis menggunakan tata nama satuan litostratigrafi tidak resmi yaitu satuan batuan. Penamaan satuan batuan ini berdasarkan atas ciri-ciri fisik batuan yang diamati di lapangan yang meliputi jenis batuan, keseragaman jenis batuan, serta posisi stratigrafi antar batuan.

Dalam penamaan stratigrafi di daerah penelitian, batuan dikelompokkan menurut lithostratigrafi dengan menggunakan tatanan satuan tidak resmi (Sandi Stratigrafi Indonesia, 1973). Penamaan satuan stratigrafi berdasarkan pada ciri - ciri litologi atau gejala batuan yang diamati di lapangan, meliputi jenis batuan dan kombinasinya, keseragaman gejala litologi dan gejala lain dalam tubuh batuan, serta posisi stratigrafi antar satuan batuan.

Berdasarkan hal tersebut, maka daerah pemetaan dapat dibedakan menjadi lima satuan batuan, sebagai berikut:

1. Satuan batu Gamping

2. Satuan Intrusi Granit

\section{Satuan Batu Gamping}

Karst merupakan salah satu bentuk pelapukan kimiawi. Karst adalah daerah yang terdiri atas batuan gamping yang berpori sehingga apabila ada air di permukaan maka akan selalu merembes ke dalam tanah. Pada 
Secara lengkap deskripsi megaskopis dari batu gamping ini, yaitu warna segar putih, warna lapuk cokelat, struktur berlubang lubang akibat pelarutan, besar butir halus, bentuk butir membundar - membundar tanggung, kemas terbuka, komposisi penyusun batuan terdiri dari alga dan foram. Sayatan petrografi batuan karbonat berupa batugamping (Packstone), kemas tertutup, terpilah sedang, kontak antar butir berupa point contact - suture contact, fragmen yang teramati berupa foraminifera kecil, moluska, dan alga yang sebagian besar telah mengalami mikritisasi, selain itu terdapat fragmen berupa kalsit. Matriks berupa mikrit, sebagian telah terubah oleh mineral sekunder dan sebagian telah mengalami oksidasi.
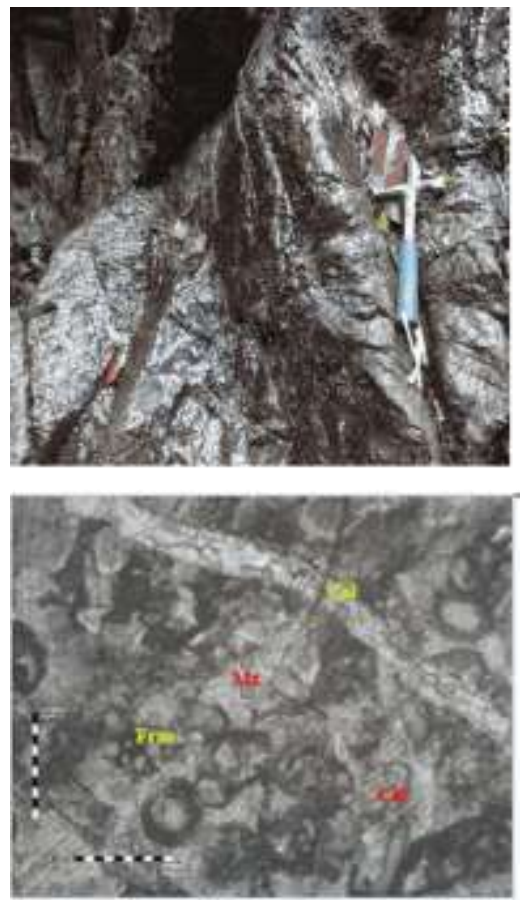

Gambar 11. Kenampakan Sampel Batuan Secara Megaskopis dan Mikroskopis

\section{Umur dan Lingkungan Pengendapan}

Untuk menentukan umur satuan ini diperlukan kesebandingan dari peneliti terdahulu, yaitu Pusat Penelitian dan Pengembangan Geologi, 1995, dimana umur satuan gamping ini adalah perm - karbon.
Penentuan lingkungan pengendapan, dilihat dari penyebarannya yang hanya menempati topografi yang relatif agak curam. Lingkungan pengendapannya adalah laut. Berdasarkan hasil rekonstruksi penampang geologi, maka umur satuan ini perm - karbon. Satuan gamping ini menempati posisi stratigrafi paling tua di daerah penelitian.

\section{Kesebandingan Regional}

Dari hasil pengamatan litologi secara megaskopis di lapangan serta hasil rekonstruksi pada penampang geologi, dan analisis posisi stratigrafi terhadap batuan lainnya yang kemudian disebandingkan dengan peneliti terdahulu, maka satuan gamping yang tersingkap di daerah penelitian ini dapat disebandingkan dengan Formasi Kuantan.

\section{Satuan Intrusi Batu Beku Granit Litologi dan Penyebaran}

Granit merupakan batuan yang bersentuhan langsung dengan satuan batu gamping yang telah dibahas dan merupakan satuan tertua yang tersingkap di daerah penelitian. Kenampakannya dilapangan berupa terobosan atau intrusi di Gunung mambul dan pada area rekahan batuan di sungai kuantan, yang berada di tenggah daerah penelitian dan bersentuhan dengan satuan batugamping.

Intrusi granit tersusun atas batuan intrusi yang memiliki warna lapuk abu-abu, warna segar abu-abu keputihan, hipokristalin, Porfiritik - faneritik, inequigranular, keras, struktur masif. Komposisi mineral yang dapat terlihat adalah kuarsa,plagioklas, feldspar dan terlihat mineral gelas.

Sayatan batuan beku berupa granit, holokristalin, equigranular, fenokris yang teramati berupa kuarsa, biotit dan plagioklas, sebagian fenokris telah terubah dan mengalami oksidasi. Intensitas alterasi lemah dengan tingkat pelapukan tinggi. Mineral 
ubahan yang hadir berupa kalsit, kuarsa, oksida besi, serisit, dan mineral opak. Terdapat veinlet dan rekahan yang terisi kalsit dan muskovit.
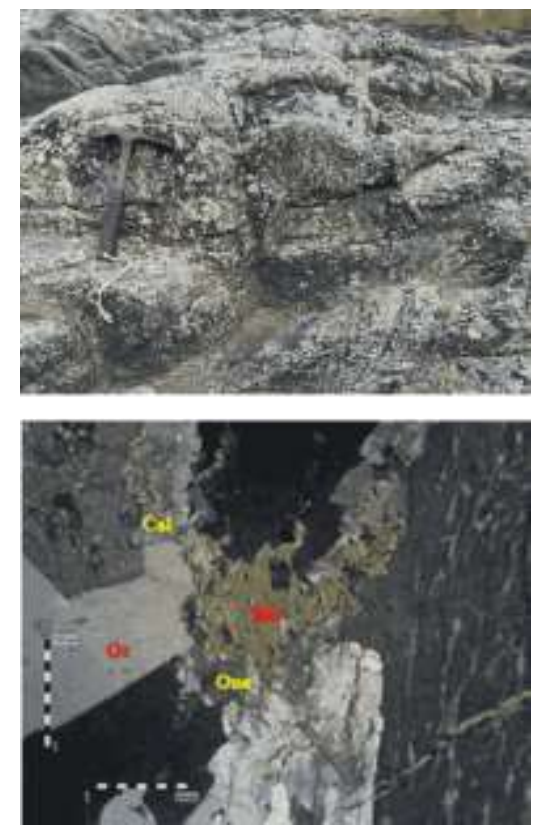

Gambar 12. Kenampakan Sample Batuan Secara megaskopis dan Mikroskopis

\section{Umur dan Lingkungan Pengendapan}

Dengan kondisi dilapangan dimana intrusi granit ini bersentuhan langsung dengan satuan gamping, maka asumsi pertama adalah intrusi ini terbentuk setelah sedimentasi gamping, yaitu setelah melewati periode perm - karbon, hal ini didukung dengan efek pemanggangan pada batuan sekitar. Dari sayatan tipis granit memperlihatkan tekstur porfiritik dengan keberadaan mineral bervariasi dalam ukuran dan bersifat hipokristalin.

Hal ini menunjukan sifat batuan yang menengah, dimana pada pembentukannya cenderung tidak lambat sehingga kristal yang terbentuk hanya sebagian dan tidak merata, lingkungan yang memungkinkan batuan ini terbentuk yaitu tidak jauh dari permukaan.

\section{Kesebandingan Regional}

Dengan memperhatikan karakteristik intrusi granit di daerah penelitian, dibandingkan dengan intrusi batu beku pada Peta Pusat Penelitian dan Pengembangan Geologi, 1995, maka dapat dikorelasikan. Namun intrusi yang diidentifikasikan mempunyai jenis batuan beku asam yang berada di daerah penelitian.

\section{Struktur Geologi}

Struktur geologi yang berkembang di daerah penelitian merupakan bagian dari struktur geologi regional. Sehingga jenis struktur dan arah umum strukturnya tidak jauh berbeda dengan pola struktur geologi regionalnya. Struktur geologi merupakan hal penting untuk mengetahui geologi suatu daerah dapat diketahui dengan memperhatikan indikasi - indikasi struktur di lapangan seperti arah jurus dan kemiringan batuan yang bervariasi, offset litologi dan bidang sesar, serta zona - zona hancuran akibat pergeseran batuan. Selain data lapangan, data tidak langsung seperti analisis topografi, analisis struktur dan penampang digunakan demi menunjang intepretasi akhir kesimpulan struktur daerah pemetaan.

Rekonstruksi struktur daerah pemetaan selain melalui data singkapan yang diketemukan juga melalui analisis morfologi sekitar daerah yang terkena pengaruh struktur, misalnya dari perubahan arah aliran sungai yang tiba-tiba (anomali), bentuk perbukitan yang khas, maupun dari kelurusan punggungan.Sistem penamaan struktur didasarkan pada letak atau geografi yang memungkinkan struktur tersebut teramati dengan baik.

Dari hasil pengamatan, pada daerah penelitian terdapat sesar (fault). Keberadaan sesar didukung oleh data penunjang, seperti jurus pelapisan batuan, pergerakan litologi, kekar, zona hancuran.. Selain itu, interpretasi struktur geologi juga didukung oleh pola-pola 
kelurusan yang terlihat pada citra DEM (Digital Elevation Model), pembelokan aliran sungai, dan analisis topografi.Berikut struktur geologi yang berkembang pada daerah penelitian meliputi :

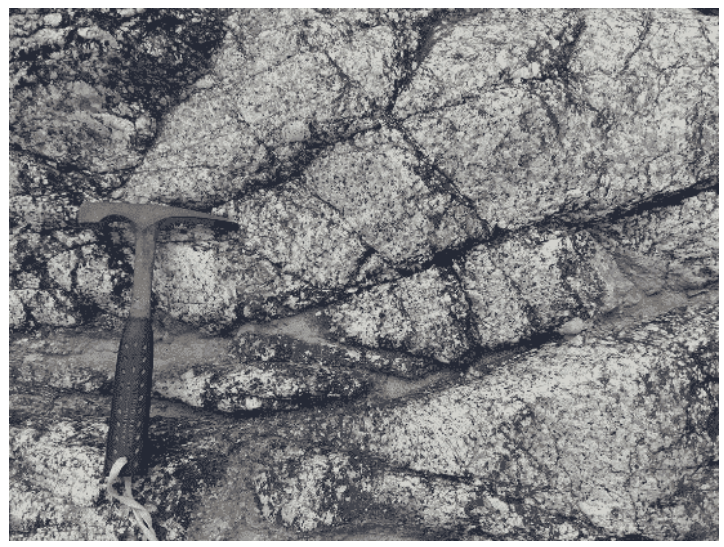

Gambar 13. Kenampakan Struktur Kekar Pada Lokasi Penelitian

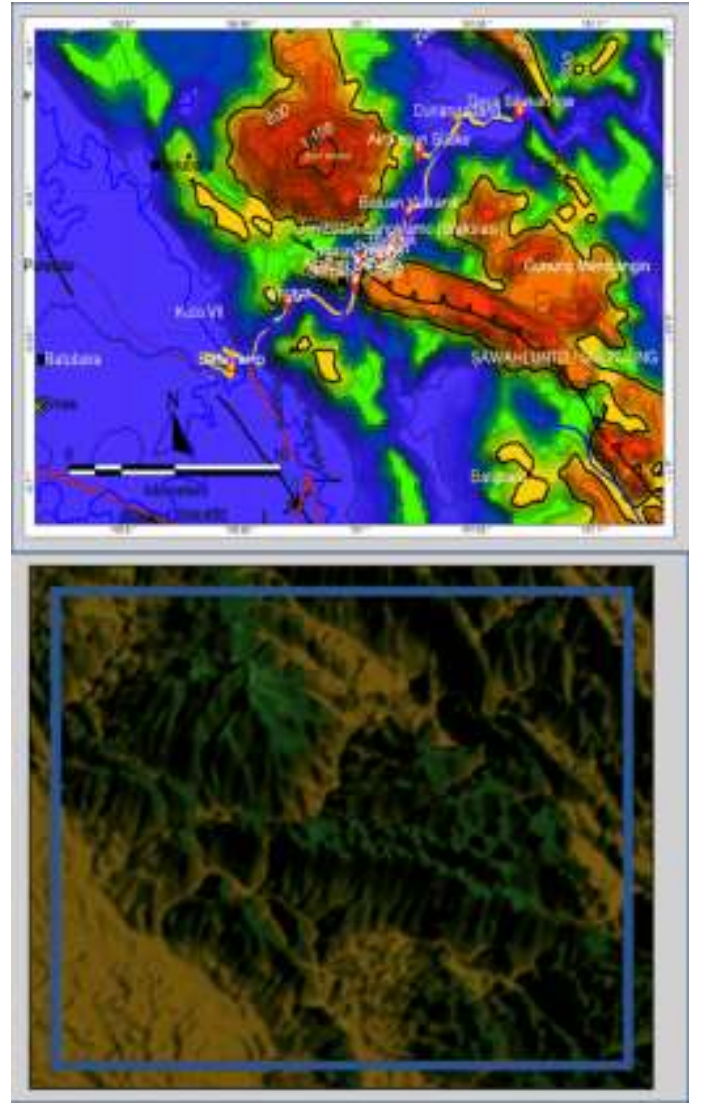

Gambar 14. Kenampakan Map View Lokasi Penelitian

\section{Geowisata}

\section{Pesona Jejak Batuan Laut Purba}

Terbentuknya kawasan karst di silokek tidak terlepas dari adanya proses pelapukan pada wilayah tersebut .Pelapukan adalah peristiwa penghancuran massa bantuan,baik secara fisik,kimiawi,maupun secara biologis. Jika dikaji prosesnya, pelapukan yang terjadi di Ngalau Basurek adalah sebagai akibat adanya pelapukan secara kimiawi. Pelapukan kimiawi yaitu proses pelapukan masa batuan yang disertai dengan perubahan susunan kimiawi batuan yang lapuk tersebut. Proses yang terjadi dalam pelapukan kimiawi ini disebut juga dengan nama Dekomposisi.

Karst merupakan salah satu bentuk pelapukan kimiawi. Karst adalah daerah yang terdiri atas batuan gamping yang berpori sehingga apabila ada air di permukaan maka akan selalu merembes ke dalam tanah. Gejala atau bentuk-bentuk alam yang terjadi di daerah karst diantaranya yaitu: dolina (lubang-lubang yang berbentuk corong), ponor (lubang yang air tanahnya dalam), goa dan sungai bawah tanah, Stalaktit (batuan yang bergantungan pada atap goa), stalakmit (batuan yang berada didasar goa).

Stalaktit dan stalakmit adalah bentuk alam khas di daerah karst. Stalaktit dan stalakmit terbentuk akibat dari proses pelarutan air di daerah kapur yang berlangsung secara terus menerus. Air yang larut di daerah karst akan masuk kelubanglubang kemudian turun ke goa dan menetesnetes dari atap goa ke dasar gua. Tetesan air ini lama-lama berubah jadi batuan yang bentuknya runcing-runcing seperti tetesan air. Stalaktit adalah batu yang terbentuk di atap goa, bentuknya meruncing kebawah, sedangkan stalakmit merupakan batu yang terbentuk di dasar goa bentuknya meruncing ke atas. 
Pesona Basement Granit Sebagai Lantai Pulau Sumatera

Di daerah Silokek ini tersingkap batuan dasar (basement) dari Cekungan Ombilin. basement ini merupakan granite yang berumur Triassic-Jurrasic dengan deskripsi batuan abu-abu kemerahan, segar, euhedral-subhedral, fanerik, mineral kuarsa, ortoklas, felsik, mika. Pola dari rekahan di basement granite ini ada dua yaitu NW-SE dan NE-SW yang saling berpasangan (konjugasi). Jenis rekahan disini didominasi oleh shear fracture dan gash fracture.

Kawasan air terjun ini merupakan bagian dari kawasan Geopark Silokek, kawasan ini memiliki hamparan hutan hujantropis yang lebat dengan aneka ragam jenis flora dan fauna. Air terjun adalah formasi geologi dari arus air yang mengalir melalui suatu formasi bebatuan yang mengalami erosi dan jatuh ke bawah dari ketinggian. Beberapa air terjun terbentuk di lingkungan pegunungan di mana erosi kerap terjadi. Air terjun terbentuk dari adanya patahan atau turunnya suatu perlapisan batuan secara tiba tiba yang dilalui oleh aliran air. Umumnya air terjun dijumpai akibat adanya sesar normal.

\section{Kegiatan Wisata Konsep Geopark Alam}

Objek-objek warisan Bumi di dalam Geopark berpeluang menciptakan nilai ekonomi.Pengembangan ekonomi lokal melalui kegiatan pariwisata berbasis alam (geologi) atau geowisata merupakan salah satu pilihan.Penyelenggaraan kegiatan pariwisata Geopark secara berkelanjutan dimaknai sebagai kegiatan dan upaya penyeimbangan antara pembangunan ekonomi dengan usaha konservasi.

Geopark Nasional Silokek di Kabupaten Sijunjung, Sumatera Barat, merupakan kawasan wisata alam yang sarat dengan pemandangan yang indah. Selain dikelilingi dengan perbukitan karst yang tinggi menjulang, kawasan geopark ini juga memiliki air terjun di antara tebing bebatuan. Batuan alam yang terdapat di geopark ini merupakan hasil sedimentasi berbagai fosil, patahan, dan lempengan bumi puluhan juta tahun silam. Dari sisi biodiversity $\mathrm{dn}$ culturediversity para wisatwan dapat menikmati paket -paket wisata dengan tema menarik yang penulis tawarkan dengan sambil mengenal budaya di kawasan Geopark Nasional Silokek.

\section{KESIMPULAN}

1. Dari penelitian ini dapat disimpulkan sebagai berikut:

Berdasarkan kemiringan lerengnya, satuan geomorfologi daerah penelitian terbagi menjadi tiga satuan, yaitu :

- Satuan Geomorfologi Pedataran Aluvium

- Satuan Geomorfologi Perbukitan Struktural

- Satuan Geomorfologi Denudasional

- Satuan Geomorfologi karst

2. Geologi daerah penelitian berupa Satuan Batugamping, Satuan Intrusi Granit

3. Geowisata Pada Kawasan Geopark Silokek berupa : Pesona Jejak Batuan Laut Purba, Pesona Basement Granit Sebagai Lantai Pulau Sumatera.

\section{DAFTAR PUSTAKA}

Ahman Sya, M. Geologi Pariwisata. Bandung: Universitas BSI Press. 2012.

Barber, A.J., Crow, M.J., dan Milson, J.S. (eds). Sumatera : Geology, Resources and Tektonic Evolution, Geological Society, Memoir, 31. 2005.

Bemmbelen, R.W. van. The geology of Indonesia. Martinus-Nijhoff, The Hague. , 1970. 
Dowling, R., \& Newsome, D. Chapter 1. Geotourism: A global activity. Global Geotourism Perspectives. Goodfellow London. 2010.

Fadhly, Ahmad. 2019. Geowisata Sumatera Barat, Dinas Pariwisata Sumatera Barat. 2019.

Oktariadi, oki. Warisan Geologi Ranah Minang. Sumatera Barat. 2016.

Irzon, R., Sendjaja, P., Kurnia, Imtihanah \& Soebandrio, J. Kandungan Rare Earth Elements dalam Tailing Tambang Timah di Pulau Singkep. Jurnal Geologi dan Sumberdaya Mineral Vol 15 (3) : 143-151. 2014.

Irzon, R. Genesis Granit Muncung dari Pulau Lingga Berdasarkan Data Geokimia dan Mikroskopis. Jurnal Geologi dan Sumberdaya Mineral Vol 16 (3) :141149. 2015.

Pulunggono, A., The changing pattern of ideas on Sundaland within the last hundred years and its implication to oil exploration. In : Indonesia Petroleum Association, Proceeding of the 15th Annual Convention, Jakarta, 1986 I. 187-214. 1985.

Rosana, Mega F \& Prodjosumarto P, Pengantar praktikum Mineral Optik, UNPAD, Tidak diterbitkan. 1998.

Rosidi, H.M.D., Tjokrosapoetro, S., Pendowo, B., Gafoer, S., dan Suharsono: Peta Geologi Lembar Painan dan Bagian
Timur Lembar Muarasiberut, Pusat Penelitian dan Pengembangan Geologi, Bandung. 1996.

Setia G.Doddy. Mineral dan batuan, NOVA Bandung. 1987.

Silitonga, P. H. dan Kartowo. Peta Geologi Lembar Solok, Sumatra. Pusat Penelitian dan Pengembangan Geologi. 1975.

Simangunsong, H., Ernowo, Oktaviani, P., Kisman., Sunuhadi, D.W. The Development of GIS for Mineral Potensial Mapping in The Eastern Indonesia. Pusat Sumber Daya Geologi. Bandung. 2012.

Suprapto, JS. Geokimia Endapan Sungai Aktif Prospek Mineralisasi Logam Daerah Kabupaten Solok, Sumatera Barat. Fakultas Teknik Geologi, Universitas Padjadjaran. Bandung. 2013.

Zuidam, R.A. \& Zuidam Cancelado, F.I. Terrain Analysis and Classification Using Areal Photographs, A Geomorphologycal Approach, Netherland, Enschede: ITC. 1985. 